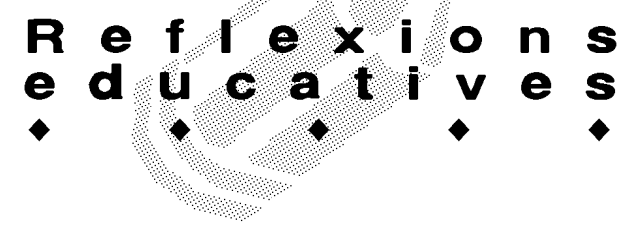

\title{
EL MASSATGE I LA SEVA INCIDÈNCIA EN EL DESENVOLUPAMENT INTEGRAL DE L'INFANT DE $O$ A 3 ANYS
}

\author{
Cori Camps Llauradó. Àrea de Psicologia Evolutiva i de I'Educació. URV
}

\author{
"Encontramos en cada ser humano una nostalgia \\ de un contacto piel a piel que permitiría una lectura \\ directa de los pensamientos, de los sentimientos, de \\ las imágenes del otro". \\ D.Anzieu \\ Elyo piel
}

"Les carícies, els contactes pell a pell, els massatges, tot això alimenta l'infant. És un aliment tan necessari com els minerals, les vitamines i les proteïnes".

Frédérick Leboyer

Amb aquest article volem presentar el massatge com una tècnica que, en mans dels mestres i professionals de l'educació infantil, pot contribuir al desenvolupament integral de l'infant, tant a nivell fisiològic com psicològic, especialment en el primer cicle 0-3 anys. Per això ens centrarem en aquest període d'edat, encara que el massatge constitueixi una tècnica igualment beneficiosa en el segon cicle d'educació infantil i, en general, a qualsevol edat. El massatge pot incloure's també en la programació com una tècnica que ajuda a desenvolupar determinats aspectes psicomotrius.

\section{Beneficis del massatge}

Per als nens i nenes el massatge és molt més que una simple experiència agradable i sensual o un tipus de teràpia física. És una forma de complementar la salut i el benestar a nivell integral (físic, psíquic i energètic).

Diferents autors (AHR, 1998; SCHNEIDER, 1991; WALKER, 1988; PORRES, 1993) han posat de manifest els beneficis del massatge infantil:

- Estimula les funcions respiratòria, circulatòria $\mathrm{i}$ gastrointestinal, millorant les incomoditats produïdes per gasos, còlics o restrenyiment $i$ afavorint l'eliminació de toxines.

- Estimula el sistema immunològic.

- Afavoreix la connexió entre els hemisferis cerebrals.
- Disminueix l'hormona ACTH (hormona adrenocorticotroòpica, produïda per la glàndula pituïtària en situacions d'estrès), prevenint l'estrès.

- Allibera endorfines, prolactina i oxitocina.

- Ajuda a desenvolupar la mielinització del cervell i el sistema nerviós.

- Estimula la coordinació i flexibilitat muscular.

- Permet relaxar i/o tonificar els músculs.

- Estimula els sentits.

- Afavoreix el son.

- Ajuda a prendre consciència, conèixer i viure amb plaer el propi cos: esquema corporal.

- Intensifica la comunicació afectiva entre el nen i les persones del seu entorn, ajudant al reconeixement de l'altre i a l'establiment de vincles (diàleg tònic).

- Augmenta el benestar i l'energia corporal.

Els beneficis del massatge anirien, doncs, des d'aquells més fisiològics fins als més psicològics, i els dividim en 4 categories: estimulació, relaxació, alleugeriment i interacció.

A nivell fisiològic, diferents treballs experimentals fets amb animals (PORRES, 1993 i SCHNEIDER, 1991) han demostrat que l'estimulació cutània en els mamífers té una funció important en totes les fases del desenvolupament, però la seva transcendència és decisiva en els primers dies de vida, ja que té una gran importància en el sistema immunològic, augmentant considerablement la resistència a les malalties infeccioses. Investigacions fetes amb humans han posat en evidència que si el nen no rep atenció emocional i contacte físic, es produeix una extrema susceptibilitat a les infeccions i les malalties. Spitz (1969) va descriure el marasme o hospitalisme (en nens que van ser privats d'establir relacions d'objecte) i la depressió anaclítica (en infants que sí que havien pogut establir el vincle, però que entre el 6è i 8è mes de vida havien estat separats de l'objecte libidinal). Tots ells presentaven (encara que amb simptomatologia diferenciada) un retard important, tant a nivell fisiològic com psicològic. Aquest treball, juntament amb altres 


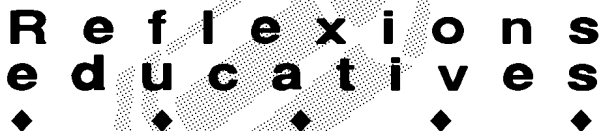

investigacions, va ser una crida d'atenció sobre la importància del contacte en els primers mesos de vida.

S'ha comprovat que els infants que reben massatges desenvolupen de forma més ràpida la maduració del sistema nerviós, ja que l'estimulació sensorial que proporciona accelera el procés de mielinització del cervell.

Durant els primers mesos de vida, els nens es van "desenroscant" a partir de la posició fetal. El massatge és especialment apropiat en aquest moment, ja que estimula la coordinació muscular i la flexibilitat necessàries, preparant-los bé per desenvolupar les seves capacitats físiques amb la coordinació adient. Afavoreix l'elasticitat i la resistència muscular. També és important quan el nen està assolint la postura erecta i la marxa (WALKER, 1988).

Des d'un punt de vista físic, el massatge actua en els éssers humans com ho fan les llepades en els animals, ja que ambdós serveixen per a estimular els sistemes fisiològics i per a vincular la cria amb la mare.

Des del punt de vista psicològic, el massatge és una de les experiències de relaxació més efectives que poden oferir-se al nen, i l' ajuda també a poder processar la informació d'entrada i respondre a ella de forma relaxada. El massatge eleva també e/llindar d'estimulació, actuant com a prevenció enfront l'estrès (SCHNEIDER, 1991). En aquest sentit, amb el massatge busquem l'equilibri tensió-distensió, ja que comencem amb un estat d'alerta per passar després a un estat de relaxació. Si no hi ha moments de relaxació, l'infant no pot processar i integrar els estímuls que rep. Afavoreix també la comunicació no verbal i l'establiment de vincles amb l'adult, i l'ajuda en la construcció de l'esquema corporal. En els següents apartats ens centrarem en aquests beneficis psicològics del massatge.

Cal dir que el massatge no només aporta beneficis a qui el rep. La persona que el dóna també es relaxa i es tranquil-litza, disminueix la pressió arterial i se sent bé pel fet de donar afecte, augmenta la vinculació i connexió amb el nen i la capacitat d'escoltar-lo.

\section{Importància de la pell, el tacte i l'estimulació cutània}

A la cultura occidental el contacte corporal directe està molt més restringit que en altres societats (la Xina, I'Índia) que estan més orientades cap al tacte. En algunes

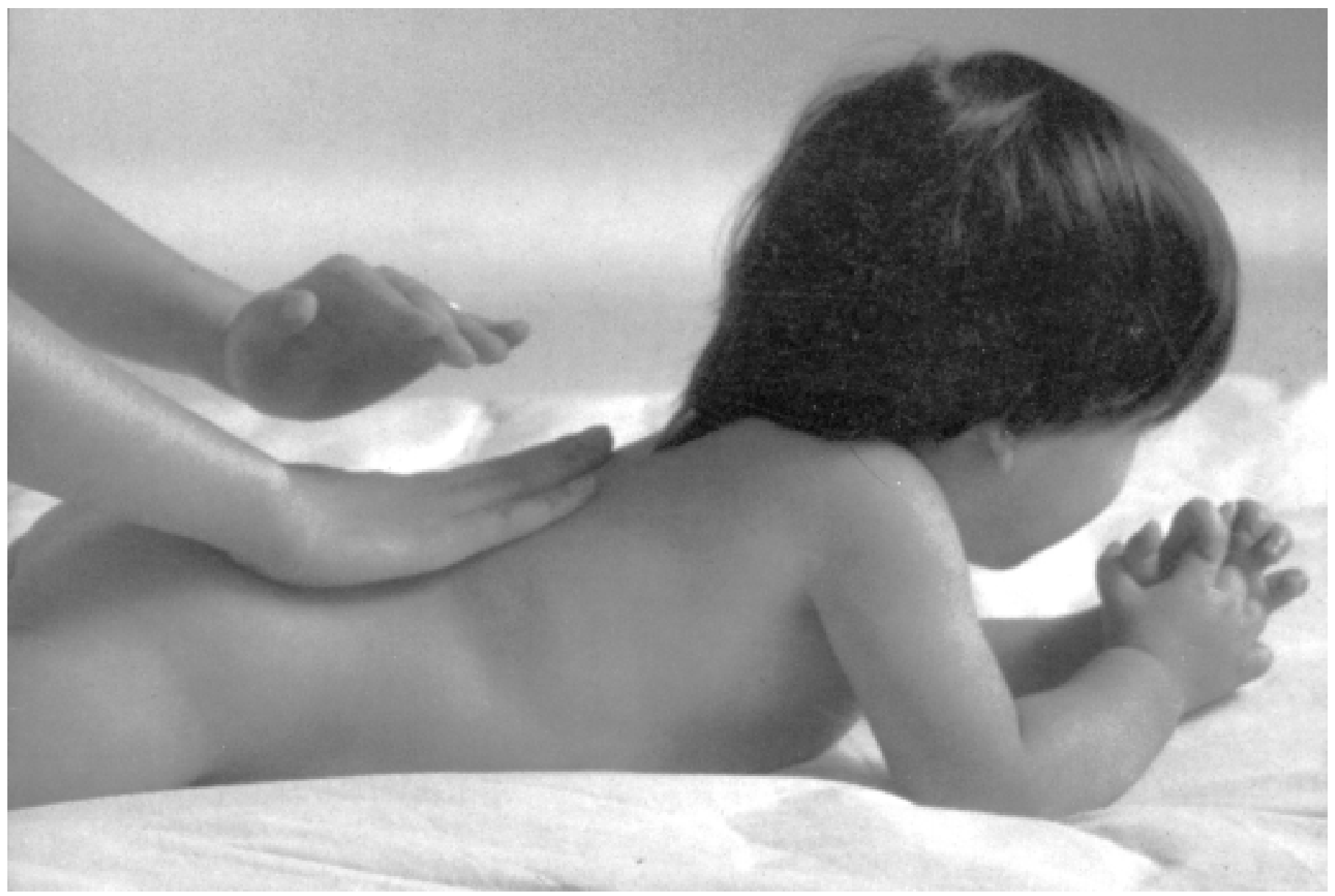




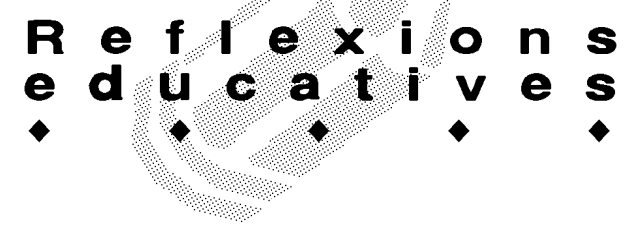

d'elles el massatge és una de les vies principals del procés de socialització i de contacte amb la comunitat. Per exemple, a l'Índia el massatge és la primera ajuda que rep l'organisme després del naixement. Hi ha el costum de fer massatge corporal des del primer dia de vida fins al voltant dels 3 anys. Després dels 3 anys la rutina canvia i el massatge s'aplica una o dues vegades per setmana, fins al voltant dels 6 anys. Llavors el nen ja està preparat per donar massatge als altres i rebre'n a canvi. (JOHARI, 2001).

És veritat que una de les funcions de la pell és protegir-nos del món exterior, però també ens permet comunicar-nos. Un contacte físic adient comunica més que les paraules. Enfrontar-se al tacte significa compartir sentiments amb els altres i ens ajuda a acceptar el nostre món intern, que es reflecteix en la manera com toquem i com permetem ser tocats. Ser capaços de sentir a través del tacte i aprendre a tocar de manera conscient i agradable ens permet retrobar la sensibilitat a nivell tàctil. (PLASENCIA, 2001).

Els sentits de l'infant es desenvolupen en forma seqüencial: primer els que actuen de forma pròxima $\mathrm{i}$ després els que ho fan de manera més distant. Dels primers, el més important és el tacte. L'estimulació cutània és molt important en el nadó, ja que la pell i el tacte són els primers mitjans de relació amb el seu entorn. És el primer sentit que es desenvolupa i és el mitjà de comunicació predominant per al bebè. El sentit del tacte ha estat detectat ja en embrions de 8 setmanes. El massatge comença ja en el ventre de la mare. Durant la gestació, la comunicació del fetus amb la mare es produeix a través del tacte i la veu, fent-li la sensació de tranquil-litat i seguretat. Una vegada ha nascut, el massatge li recorda aquestes mateixes sensacions. El tacte seguirà essent el sentit més complet i madur. Tots els nens responen a la manera com se'ls toca i se'ls mou (WALKER, 1988). Tal com diu A. Bachs (2001), "la pell és una finestra que es pot obrir o tancar al contacte, a la relació, a la intimitat. El massatge suposa una resposta constructiva i gratificant a les necessitats de contacte físic que té el nadó". El contacte físic com a mitjà de comunicació s'aprèn des de la infància i persisteix tota la vida.

Altres sentits pròxims són el gust i l'olfacte, ambdós connectats amb el tacte i molt importants en el nadó. Els sentits a distància (vista i oïda) són també importants per a la vinculació emotiva del nen amb la mare, però el sentit del tacte té un impacte encara més gran per a la vinculació amb la mare.

Atès que el tacte és un sentit tant desenvolupat en el nen petit, comprendrem la importància de poder-lo estimular. Si aquesta estimulació va acompanyada d'emoció, aportarà beneficis importants al bebè o al nen més gran. En aquest sentit, el massatge infantil proporciona experiències sensorials fascinants: els ulls de la mare, el contorn dels seus cabells, el seu somriure, la seva olor, el to de la seva veu o l'extraordinària estimulació vestibular (SCHNEIDER, 1991).

El massatge és, en definitiva, una forma ampliada del tacte, que ens pot permetre desenvolupar els diferents sistemes i al mateix temps afavorir la comunicació i tenir una comprensió més gran dels nostres infants. És una forma d'escolta del nen i de disponibilitat per part de l'adult, que afavoreix la formació de vincles, tal com veurem a continuació.

\section{To muscular, afecte i comunicació: l'àmbit dels senti- ments. Diàleg tònic i formació del vincle afectiu amb l'altre}

El to muscular i el diàleg tònic durant el primer any de vida és fonamental per al desenvolupament emocional de l'infant. En aquest apartat veurem com es construeix aquest primer diàleg. Cal tenir en compte que parlem també de diàleg tònic en relació amb el vincle entre la mestra i l'infant, una vegada aquest entra a la llar d'infants. El massatge pot ser una eina per a la formació d'aquest vincle.

Wallon va posar de manifest la importància de la fusió afectiva primitiva en el desenvolupament de l'infant, fusió que s'expressa a través del moviment en un diàleg que és el preludi del diàleg verbal ulterior i al qual anomenem diàleg tònic (i des de la psicoanàlisi parlaríem de "relacions objectals").

El diàleg tònic s'elabora a partir de les necessitats vitals per part de l'infant i la seva satisfacció. Aquesta satisfacció o la seva absència remet a un "altre" (normalment, la mare). En funció de la resposta a aquest impuls, el nen viu un moviment interior agradable si hi ha satisfacció (plaer), o un moviment interior desagradable si no hi ha satisfacció (desplaer, patiment).

Veiem de forma ràpida com es produeix aquest diàleg tònic (amb més detall, podeu veure CAMPS, 2002). Durant el primer any de vida, les necessitats del nen i la nena i la seva satisfacció es manifestaran a través del to muscular, i es traduiran en hipertonia (contracció forta) o hipotonia (decontracció en estat de repòs). També les alternances presència-absència, proximitatllunyania, contacte-separació tindran la seva manifestació tònica i emocional. És el que s'anomena "hipertonia de crida" i "hipotonia de distensió". La primera s'associa a una fase de necessitats i tensió (crisi de tensió tònicoemocional) i la segona a la seva satisfacció i a la distensió (relaxament tònic). Qualsevol tipus de carència, de mal, de necessitat, es traduirà en el nen en una hipertonia, 


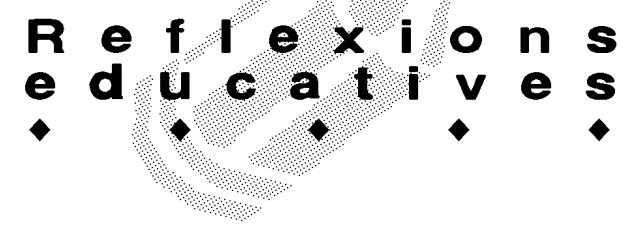

mentre que la seva satisfacció es traduirà en una hipotonia.

Aquestes seqüències repetides són les premisses del diàleg tònic que es construeix sobre les variants del to, acompanyant els sentiments, les necessitats, els contactes, les experiències sensorials $\mathrm{i}$ emocionals, diferenciant a poc a poc l'interior de l'exterior del cos (GAUBERTI, 1993).

En aquesta alternança hipertonia-hipotonia el to madura normalment. De la forma com el nen passi d'una fase a l'altra dependrà l'establiment d'un diàleg tònic adient amb la mare, que constituirà la base de les conductes emocionals futures.

Quan el nadó rep les atencions de la mare, aquesta actua sobre el nen, però també ell actua sobre ella. Quan la mare alimenta el bebè, aquesta acció provoca una transformació del cos del nen i provoca també una transformació en ella. El to de l'adult també es modifica. És el que Aucouturier (2001) anomena ressonància tònicoemocional recíproca. Si el nen pot actuar sobre la seva mare amb plaer i aquesta rep la seva acció amb plaer, es deixa transformar; aquest plaer de la transformació dels dos garanteix la precocitat del procés d'individualització, a partir de la fusió primitiva.
Aquestes empremtes de plaer que graven el cos del bebè, junt amb la qualitat de l'investiment dels altres sobre el nen (procés d'acció-interacció-transformació), constituiran l'origen del seu continent psíquic, de la seva unitat de plaer i progressivament aniran configurant la seva totalitat corporal (AUCOUTURIER, 1997), la qual el portarà cap a la construcció de la seva identitat personal. Segons Rota (2001), aquesta identitat es construeix a partir de la vivència i la percepció del propi cos, de la formació i reconeixement de la pròpia imatge corporal. I serà a partir de la conquesta d'aquesta identitat que el nen podrà establir unes relacions diferenciades amb els altres. Per tant, el procés d'identitat anirà paral-lel al procés de diferenciació del nen en relació amb el seu entorn maternal. La identitat personal es construeix interactuant amb l'entorn.

Tal com veiem, en l'establiment dels vincles és molt important la comunicació no verbal, tònica, la qual cosa ens remet al massatge com una eina que permet actualitzar el diàleg tònic entre la mestra, afavorint tant el procés de vinculació (afecte, calor...) com la separació de l'adult. En aquest sentit, el massatge permet una transformació mútua del nen i de la mestra, ajustant les seves tensions tòniques a través d'un procés d'escolta

TOTALITAT CORPORAL

Es manifesta en l'expressivitat psicomotriu

\section{ESQUEMA CORPORAL}

(cos real)

- Més vinculat als aspectes motrius i cognitius (cos instrumental).

- Conscient.

- Igual per a tots.

- Acaba al voltant dels 12 anys.

- Sotmès a lleis neurològiques $\mathrm{i}$ maduratives.

\section{IMATGE CORPORAL \\ (cos imaginari)}

- Més vinculat als aspectes emocionals i fantasmàtics.

Inconscient (imatges gravades a partir de sensacions viscudes $i$ com ha investit el cos).

- Diferent per a cadascú.

- No acaba mai.

- Vinculat a les relacions tònicoemocionals viscudes (història de la relació). 


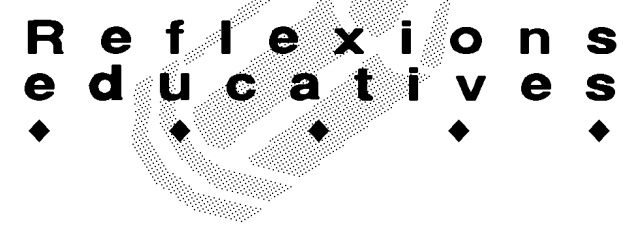

del nen o nena per part de l'adult. Tal com diu Schneider (1991), el massatge infantil facilita els vincles afectius perquè inclou els elements principals per a establir-los: contacte amb la mirada, contacte pell a pell, somriure, sons, abraçades, carícies, olor, resposta als estímuls i interacció.

\section{L'estimulació de la sensibilitat en la construcció de la totalitat corporal de l'infant}

Hem vist la importància que té el diàleg tònic $i$ el vincle amb l'adult per a la gènesi de la totalitat corporal en l'infant, en la doble vessant, destacada per Wallon, de font d'estimulacions sensorials i del procés d'identificació diferenciació que té lloc durant la infància. En aquest apartat veurem com incideixen les estimulacions sensorials en la construcció de la totalitat corporal i de la identitat personal de l'infant. L'elaboració de la totalitat corporal, formada per l'Esquema Corporal (EC) i la Imatge Corporal (IC) és fonamental per al desenvolupament motriu, emocional i cognitiu de l'infant.

Wallon assenyala que en el nadó es produeix la dissociació entre els diferents dominis funcionals en aquest ordre: sensibilitat interoceptiva (lligada a l'alimentació i necessitats fisiològiques, amb els seus estimulants a les vísceres); sensibilitat propioceptiva (lligada a l'equilibri, les actituds i els moviments, sensacions que es localitzen en el músculs, tendons, articulacions i el laberint), i sensibilitat exteroceptiva (sensacions cutànies, gustatives, olfactives, auditives i visuals).

L'esquema corporal es constituirà sobre la base de la interocepció i de la propiocepció, en primer lloc (que provenen dels òrgans del cos) i després de l'exterocepció (que és estimulada pels objectes del món exterior); ambdós sistemes no es fusionen fins més tard amb la constitució d'un espai unificat.

Aquesta dissociació entre les sensacions internes $i$ externes permetrà al nen la pèrdua de la globalitat fusional amb la mare, i distingirà el que és ell $i$ el medi, un jo permanent i un no-jo fluctuant (LAPIERRE i AUCOUTURIER, 1980).

Totes aquestes estimulacions, juntament amb el diàleg tònic, incidiran en la formació de la totalitat corporal, la qual estarà formada per l'esquema corporal i la imatge corporal. En el quadre 1 podeu veure una síntesi dels aspectes que els defineixen. (Per a ampliació vegeu BOSCAINI, 2000; CAMPS, 2002; LEVIN, 1998).

De quina manera pot incidir el massatge en la construcció de la totalitat corporal?

En primer lloc, el massatge ajuda a l'estructuració de l'EC, ja que proporciona vivències al nen que l'ajuden a reconèixer i interioritzar les parts del seu cos, intervenint a través dels diferents tipus de sensibilitat propioceptiva (músculs, articulacions...), exteroceptiva (tacte, vista, oïda, olfacte) i fins i tot interoceptiva (indirectament, al millorar els gasos, còlics i restrenyiment).

En segon lloc, amb el massatge intervenim també en la construcció de la IC, ja que transmetem afecte, acceptació, reconeixement com a persona, establint un vincle emocional. Li oferim vivències de plaer i li possibilitem un investiment positiu del seu cos. Tal com diu Bachs (2001), amb el massatge podem preveure l'aparició d'alteracions de l'esquema corporal i facilitar el camí del plaer corporal, fent la vivència del seu cos positiva $i$, per tant, una bona base per a la vivència corporal de l'adult.

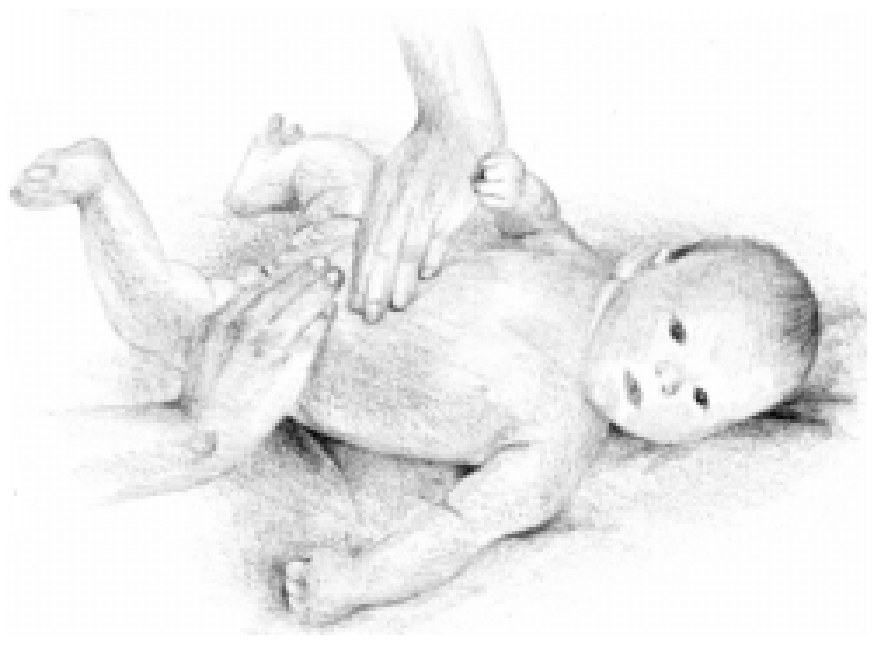

\section{Consideracions finals}

El nen durant els primers anys de vida és un ésser global, entenent per globalitat la interrelació entre els aspectes motrius, cognitius, afectius i relacionals. Al llarg de l'exposició hem pogut veure el massatge com una tècnica d'intervenció que afavoreix el desenvolupament integral de l'infant de 0 a 3 anys. Així, el massatge l'estimula en la maduració del sistema nerviós i en el desenvolupament de la seva motricitat, i l'ajuda en el control tònic. A nivell cognitiu li facilita l'atenció i l'elaboració dels estímuls que rep, i al mateix temps li permet conèixer $\mathrm{i}$ interioritzar les parts del seu cos $\mathrm{i}$ anar construint el seu esquema corporal. A nivell emocional $i$ relacional, el massatge el relaxa i intensifica la comunicació amb els altres, creant vincles basats en l'escolta i el respecte.

El massatge pot ser, doncs, una eina en mans de les mestres d'educació infantil per a contribuir al desenvolupament global de l'infant. De forma més específica, pot incidir en la majoria de continguts de l'Àrea 1 (Descoberta d'un mateix) del Currículum d'Educació Infantil, 


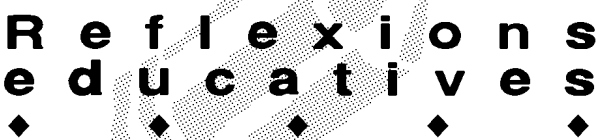

tant pel que fa a Continguts de Procediments (observació i exploració de les pròpies necessitats i possibilitats; control global i segmentari del cos; expressió i manifestació corporal), Continguts de Fets i Conceptes (possibilitats del propi cos: perceptivomotrius, afectives i cognoscitives; el propi cos: esquema coporal; noció d'identitat) i Continguts d'Actituds (iniciativa i constància en l'acció; valoració d'un mateix).

La tècnica del massatge infantil varia en les diferents propostes (vegeu, per exemple, AHR, 1998; LEBOYER, 1989; SCHNEIDER, 1991; WALKER, 1988). Per a totes elles cal un aprenentatge de les seqüències i moviments a seguir. Cal també tenir en compte que és molt important la qualitat del tacte. El massatge ha de fer-se de forma conscient, amb "presència" i amb implicació, ja que el contacte és de l'ordre de l'emoció profunda. També és molt important la mirada que l'acompanya. S'ha de connectar amb el nen abans d'iniciar el massatge, que sigui de l'ordre del plaer, que hi hagi desig. En paraules de Bachs (2001), el respecte és molt important, al fer massatge entrem en la intimitat de l'altre. El massatge no es pot fer quan un vol. Cal demanar entrada, veure si el nen està disponible o no a rebre'l i a comunicar-se. Només així fem del massatge un acte de respecte, d'escolta, de comunicació

Es també important que la persona que fa el massatge estigui tranquil.la, amb una respiració àmplia $\mathrm{i}$ profunda. Cal una disponibilitat que permeti a la mestra escoltar el nen, contenir-lo, respectar-lo, per tal de poder arribar a un ajust tònic, a una transformació recíproca i a un diàleg a través del tacte, la mirada i la veu. Per això és important que la mestra passi per un procés de formació en relació amb la seva respiració, la seva tonicitat, la seva manera de tocar $\mathrm{i}$, en definitiva, en relació amb la seva disponibilitat corporal.

En funció de l'edat serà important dedicar més o menys temps al massatge (més a les primeres edats), a diferents parts, i les tècniques seran diferents també segons els nens als quals s'adreci: per exemple, nens hipertònics o hipotònics, nens amb por al contacte, nens amb necessitats educatives especials. Podem utilitzarlo també com una via de canalització de la gelosia, en el moment de l'arribada d'un germanet. $O$, en els nens més grans, poden fer-se massatge entre ells, afavorint així els aspectes socials.

Hem fet esment, al començament, que el massatge pot ser una tècnica complementària a la psicomotricitat. Ens hem referit a diferents aspectes psicomotrius: l'esquema corporal, el to muscular, la coordinació motriu o el diàleg tònic. Si pensem en una sessió de psicomotricitat, el massatge pot ser un dels racons de la sessió, on els nens hi van quan volen. També el podem incloure dins el joc simbòlic ("anem a l'hospital a curar aquesta ferida", o "cal reparar aquest vehicle") o pot ser una intervenció específica en nens amb necessitats educatives especials.

Acabem amb les paraules de Schneider (1991): "La pràctica del massatge crea vincles de confiança i amor, és una bona lliçó de tendresa, afecte, obertura i respecte: tot un bagatge positiu".

\section{Referències bibliogràfiques}

AHR, B. Masaje para bebés. Ed. Paidotribo. Barcelona. 1989.

AUCOUTURIER, B. La acción como transformación. Actas XIV Seminario de Práctica psicomotriz. EMEIP. Barcelona. 1997.

AUCOUTURIER, B. Pertorbacions psicomotrius. Conferència impartida Departament Psicologia, URV. Tarragona. Març 20001. (no publicada).

BACHS, A. Fotocòpies Escola Municipal d'Expressió i Psicomotricitat Barcelona. 2001.

BOSCAINI (2000) "Relaciones tónico-emocionales, imagen corporal y aprendizajes en relajación". Psicomotricidad, 64, 1 (2000) 15-30. Madrid.

CAMPS, C. El esquema corporal. A LLORCA, M. i altres. La Práctica Psicomotriz. Una propuesta educativa mediante el cuerpo y el movimiento. Málaga: Ed. Aljibe. Málaga. 2000. p. 355-398.

Currículum Educació Infantil. Generalitat de Catalunya. 1992.

GAUBERTI. Mère-enfant: à corps et à vie. Ed. Masson. París. 1993.

JOHARI, H. El masaje hindú. Ed. Kairós. Barcelona. 2001.

LAPIERRE, A. i AUCOUTURIER, B. El cuerpo y el inconsciente en educación y terapia. Ed. Científico Médica. Barcelona. 1980.

LEVIN. La clínica psicomotriz. El cuerpo en el lenguaje. Ed. Nueva Visión. Buenos Aires. 1998.

LEVOYER, F. Shantala. Un arte tradicional, el masaje de los niños. Ed. Edicial. Argentina. 1989.

PLASENCIA, J. Aprende a tocar. "Cuerpomente», 108 (2001).

PORRES, E. Tócame, mamá. Ed. Edaf. Madrid. 1993.

ROTA, J. "Un caso práctico en una relación de ayuda terapéutica. Un ejemplo de la relación y lo específico entre el psicoanálisis y la psicomotricidad a través de un caso práctico". A Desarrollo e intervención psicomotriz. Actas / Congreso Estatal Psicomotricidad. FAPee. Barcelona. 2001. p. 217224.

SCHNEIDER, MC. Masaje infantil. Guia práctica para la madre y el padre. Ed. Medici. Barcelona. 1991.

SPITZ, R. El primer año de vida del niño. México: Ed. Fondo Cultura Económica. Mexico. 1969.

WALKER, P. El masaje de los niños. Ed. Integral. Barcelona. 1988. 